\title{
Is a confidence needed in learning mathematics?
}

\author{
Surya Sari Faradiba ${ }^{1}$, Alifiani $^{2}$ \\ ${ }^{1,2}$ Universitas Islam Malang, Jl. Mayjen Haryono 193 Malang, Indonesia
}

\begin{tabular}{ll}
\hline A R T I C L E I N F O & A B S T R A C T \\
Original Article & Metacognitive blindness is often found in students with \\
doi: 10.18860/ijtlm.v2i2.8443 & unsatisfactory academic performance. However, this study aims to \\
Keywords: & reveal the process of metacognitive blindness that occurs during \\
Self-confidence, Metacognitive & problem solving experienced by students with quite good academic \\
Blindness, Problem-solving, & performance. The data collected is in the form of words obtained \\
Mathematics Learning & through interviews and pictures of the work of research subjects. \\
& Description of data analysis and interpretation of the meaning of \\
& findings using text analysis. Analysis is carried out in all phases of \\
& problem solving, including analyzing, exploring, planning steps to \\
& solve problems, implementing a problem solving plan, and \\
checking again. The results of qualitative analysis show that & subjects who are students with good academic performance can \\
experience anomalous results during the problem solving process. & In this study, the anomalous result in question is a condition where \\
the subject feels anomaly during the problem solving process, & where the anomaly is actually not there. In this case, subjects who \\
have good academic performance tend to have too much & confidence. This makes the performance in the problem-solving \\
process less optimal.
\end{tabular}

(C) 2019 IJTLM. All rights reserved.

*Corresponding author.

E-mail: suryasarifaradiba@unisma.ac.id

How to cite: Faradiba, S. S., \& Alifiani. (2019). Is a confidence needed in leraning mathematics?. International Journal on Teaching and Learning Mathematics, 2(2), 52-59.

\section{INTRODUCTION}

Metacognitive ability is the main indicator in achieving learning objective (Jacobse \& Harskamp, 2012). The involvement of metacognitive ability becomes an important component in learning activity because it can encourage higher-order thinking skill (Wismath, Orr, \& Good, 2014). Metacognition is defined as a part of higher order thinking skill which includes understanding, analysis, and control of cognitive processes (Dorr \& Perels, 2019). In this case, metacognition can support students in problem-solving more effectively (Kim, Park, Moore, \& Varma, 2013) and meaningful (Hassan \& Rahman, 2012; Safari \& Arezy, 2012).

In relation to the problem-solving process, sometimes the subject is not aware of any mistakes that have been made, hereinafter referred to as metacognitive blindness (Faradiba, Sa'dijah, Parta, \& Rahardjo, 2019b). Metacognitive blindness is characterized by redflag during the problem-solving process. Redflag is a warning to pause or step back to the previous problem-solving stage, to subsequently take immediate action in the problem-solving process (Goos, Galbraith, \& Renshaw, 2000; Goos, 2002). There are three types of redflags in the problem solving process, namely lack of progress (lack of progress/LP), error detection (error detection/ED), and strange results (anomalous result/AR) (Goos, 2002).

Each of the roles of redflag in metacognitive blindness can be chosen as follows. First, the most common type of redflag is LP. LP is a problem when someone tries to solve, impasse or deadlock in the process of solving problems (Goos, 2002). This LP will cause the compilation 
of metacognitive blindness that the result is not realized by the subject. In this case, the subject does not need to be in trouble or is facing a problem that is sufficient / fine from things that are not successful in the problem-solving process. Second, the next type of redflag is ED. ED is the subject of resolution that solves errors in problem solving that require the subject to examine and correct errors (Goos, Galbraith, \& Renshaw, 2000). ED will lead to failure of metacognitive blindness compilation when subject is not considered to have an error that has been done by the subject of improving the completion process without checking or correcting the error. Third, the last type of redflag is AR. AR is a condition where the subject finds an odd / unusual condition (Goos, Galbraith, \& Renshaw, 2000; Goos, 2002; Stillman, 2004; Ng, 2010). This AR will cause metacognitive blindness when the anomaly or unusual in the problem solving process is not realized by the subject and the subject takes a stand to avoid it. Indicators of unusual presence can be known as a compilation of subjects who find conflicting information or conflicting solutions.

As far as, metacognitive blindness as a form of metacognitive failure that always occurs in students who experienced the learning problems, for example the students who experience math anxiety (Legg \& Locker, 2009; Faradiba, Sa'dijah, Parta \& Rahardjo, 2019b), students with impaired mathematics (Faradiba, Sa'dijah, Parta \& Rahardjo, 2019a), or have unsatisfactory academic pretensions (Erickson \& Heit, 2015). This study tries to uncover the phenomenon of metacognitive blindness that occurs in students with good academic achievement. The result of this research is expected to provide new insights related to metacognitive blindness as a form of metacognitive failure.

\section{METHOD}

This study aims to explore the problem and develop a detailed-understanding of the phenomenon of mathematical anxiety in relation to the process of solving mathematical problems. Data collected in this study were in the form of words obtained through the results of interviews, pictures of the results of the subject's work in solving mathematical problems to get a picture of the subject's behavior. The text analysis is used to describe the data analysis and interpretation of the meaning of findings. This kind of research is categorized as a qualitative research (Creswell, 2012; Fraenkel \& Wallen, 2006). This research is categorized in qualitative research with a case study is used as the research strategy. Case study research strategy is a strategy in which researchers investigate carefully a program, event, activity, process or group of individuals (Creswell, 2012). The case study in which is the process of solving mathematical problems carried out by the subject. In this case, the researcher explores the process to obtain the research objective, which is describing the occurrence of metacognitive blindness when solving mathematical problems experienced by students with good academic achievement.

This research was conducted on students of Mathematics Education, semester 3 of 2019/2020 Academic year, Universitas Islam Malang. The study lasted for four weeks. In the first week, researchers submit material related to mathematical problems that will be solved by the subjects. In the second week, researchers collected data related to the subject's academic achievement in a number of courses taken in the previous semester. In the third week, data collection was carried out in the form of subject work and interview results. In the fourth week, the researchers analyzed and triangulated the data.

The sampling technique used was purposive sampling in which prospective subjects were selected from students with the highest academic performance in the class. In addition, researchers who are teaching staff at the university are also one of the considerations, thus supporting data retrieval in order to obtain the results of the subject's work and interviews that truly describe the subject's condition. Next, the selected subject candidates are asked to solve mathematical problems. Mathematical problems are given to the subject of the research to reveal the existence of redflag in each stage of the process of solving mathematical problems. The mathematical problems used in this study can be seen in Figure 1. 
Pay attention to the chessboard of $8 \times 8$ square units as shown in the image below:

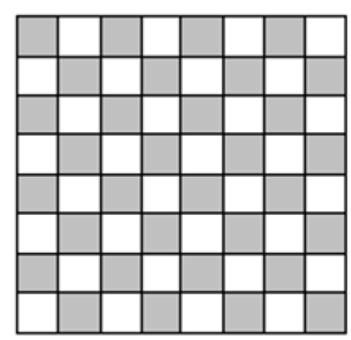

1. By paying attention to the different colors arranged on the chessboard, determine how many different kinds of squares have different sizes and color arrangements on the board!

2. Without seeing the difference in the color arrangement, determine how many squares are on the chessboard!

Figure 1. Mathematical problem in this study

The next step, the researcher analyzed the results of the prospective subject's work to ensure there is a potential for redflag that leads to metacognitive blindness based on indicators of metacognitive blindness during problem solving in Table 1 (Faradiba, Sa'dijah, Parta, \& Rahardjo, 2019b).

Table 1. Indicator of metacognitive blindness based on redflag type anamolous result

\begin{tabular}{ll}
\multicolumn{1}{c}{$\begin{array}{c}\text { Troubleshooting } \\
\text { Phase }\end{array}$} & \multicolumn{1}{c}{ Anomalous Result Indicator } \\
\hline $\begin{array}{l}\text { Understanding the } \\
\text { Problem }\end{array}$ & $\begin{array}{l}\text { The subject did not realize that the errors/peculiarities he found in solving the } \\
\text { problem actually did not exist }\end{array}$ \\
\hline $\begin{array}{l}\text { Analyzing the } \\
\text { Problem }\end{array}$ & $\begin{array}{l}\text { The subject did not realize that the errors/peculiarities he found in the process of } \\
\text { determining the connection between what was known and what was asked in } \\
\text { problem solving actually did not exist. }\end{array}$ \\
\hline $\begin{array}{l}\text { Exploring the } \\
\text { Problem }\end{array}$ & $\begin{array}{l}\text { The subject did not realize that the error/peculiarity that he found in the process } \\
\text { of determining relevant information in the way used was actually not there. }\end{array}$ \\
\hline $\begin{array}{l}\text { Planning the } \\
\text { problem-solving }\end{array}$ & $\begin{array}{l}\text { The subject did not realize that the errors/peculiarities he found in the process of } \\
\text { determining various approaches to solving the problem actually did not exist. }\end{array}$ \\
\hline $\begin{array}{l}\text { Implementing a } \\
\text { problem-solving plan }\end{array}$ & $\begin{array}{l}\text { The subject did not realize that the errors/peculiarities he found in the process of } \\
\text { determining the steps of implementing the chosen strategy actually did not exist. }\end{array}$ \\
\hline Verification & $\begin{array}{l}\text { The subject did not realize that the errors/anomalies he found in the process of } \\
\text { checking for a solution actually did not exist. }\end{array}$ \\
\hline
\end{tabular}

\section{RESULTS AND DISCUSSION}

The results of the subject's work for mathematical problems number 1 and 2 are presented in Figure 2. The subject's answer to the first problem is $8+24+8+24=64$. Meanwhile, the subject's answer to the second problem is $48+16=64$. At the end answers, the subject also states that he needs more time to find out (confirm) the size of all the squares that exist on the problem that has been presented. 


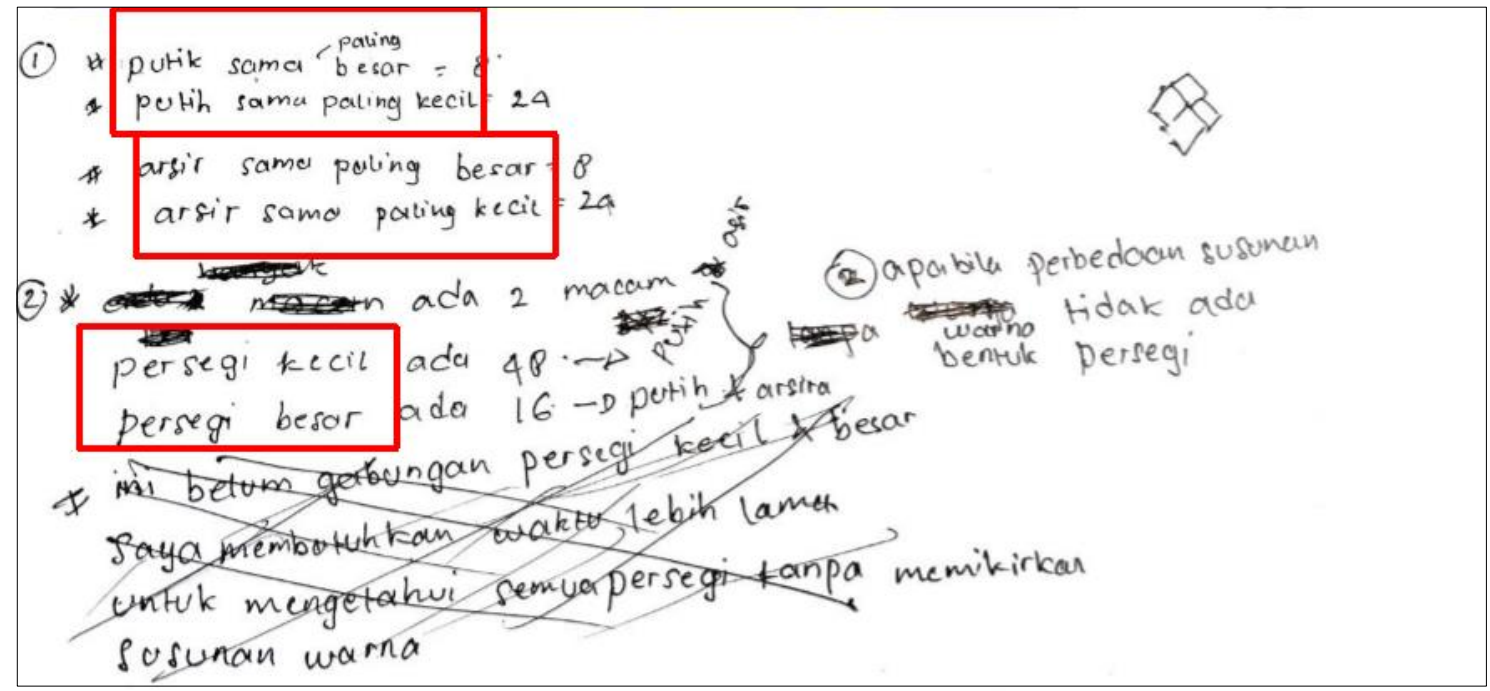

Figure 2. The result of subject's work in solving the mathematical problems

The problem solving stage by the subject in detail can be described as follows: First, the stage of understanding the problem. At this stage, the subject determines what is asked and identifies the information contained in the problem. At this stage, the subject does not experience redflag. This can be seen through the following interview transcript:

I: "What is asked in this matter?"

S: "The number of different squares that are on an $8 \times 8$ chessboard"

I: "What difference does it mean?"

S: "The difference in color is black and white and the difference in size. To ensure there is a

difference in the size, I used this small piece of paper as a reference"

In the dialogue snippet above, it can be seen that the subject does not realize that the peculiarities that he found are related to the unequal square sizes in the process of understanding the real problem does not exist. In other words, the subject experienced an AR type redflag. In this study, metacognitive blindness experienced by the subject has occurred since the early stages of problem solving. This is consistent with research Alexander et al. (1995) which states that metacognitive ability is not related to IQ. However, metacognitive ability can help subjects who have less ability or knowledge in the problem solving process. In line with this opinion, Swanson (1990) shows that the ability to solve problems is not related to IQ, but rather metacognitive. Students who have higher metacognitive ability will be able to solve problems better than those who have lower metacognitive ability.

The second stage is analyzing the problem. At this stage, the subject thought of material related to the problem and related to the material to what is asked in the problem. The process of redflags when analyzing problems can be seen in the following interview transcript:

I: "What did you first think of to solve this problem?"

S: "Square is a flat shape with the same length on all four sides. So if the unit square has a size not the same then it will not be able to form another square with a larger size. Therefore, answer for problem number one and problem number two the same, which is 64 square"

In this case, the subject did not realize that the peculiarities he found in the process of determining the number of squares actually do not exist. In other words, the subject experiences an anomalous result (AR) type redflag. This AR is a manifestation of the subject's excessive self-confidence in his ability to solve mathematical problems. In some studies, subjects who have low performance show excessive self-confidence than subjects who have higher performance (Kruger \& Dunning, 1999; Dunning et al., 2003, Miller \& Geraci, 2011). 
The third stage is exploring the problem. At this stage, $\mathrm{S} 4$ uses relevant information from the previous stage, which is about the concept of a square. This can be seen in the following interview transcript:

I: "What will you do to solve this problem?"

$S:$ "By direct count, by matching the size of this small piece of paper"

I: "How do you determine a square that is the same or different?

S: "By marking the size on this small piece of paper, if the sign is different means the square is indeed different"

At this stage, the subject still did not realize that the peculiarities that he found in the process of determining relevant information in the way used actually do not exist. This can be seen from the last dialogue that shows the subject using small pieces of paper to ensure square size. Glaser et al. (1992) provide evidence that metacognition can differ based on the problem at hand. In general, successful problem solvers use metacognitive strategies more often than less successful problem solvers. In this case, the subject did not use a metacognitive strategy which included three stages, namely: designing what was to be learned; monitor self-development in learning; and assess what is learned. The subject since the beginning of the problem solving phase only focuses on sketches of square images that he thinks are not the same, so the problem presented fails to meet the definition of a square.

The fourth stage is planning problem-solving. At this stage, the subject was thinking about approaches that can be used in finding a solution to a problem. This can be seen in the following interview transcript:

I: "Do you think there are other ways to solve this problem?"

$S:$ "Yes, you can use measuring instruments with high accuracy in millimeters and nanometers"

I: "Are you sure this method you used can be used to find the solution to the first problem?"

S: "With the limitations of the tool, I think this little piece of paper can be quite helpful"

I: "Okay, now are you sure about that way?"

S: "yes"

I: "Are there any difficulties in applying this method?

$S:$ "No, because in my opinion this is the easiest and most likely method to be applied"

At this stage, the subject still believed that the size of the square in the sketch of the image is not the same. In this case, self-regulation can help the subjects realize how much they know. However, this self-monitoring did not appear to be carried out by subjects who are overly confident. Without accurate feedback, subjects cannot choose the right self-regulation strategy to continue the problem-solving process (Dunlosky et al., 2005). Instead, the subject chooses a problem-solving strategy based on feeling of knowing about the definition of a square and judgments of learning in a hurry that related to sketches of the wrong image, both of which have been proven to be inaccurate in measuring the ability of self related to a problem (Metcalfe \& Finn, 2008). These inaccurate steps lead to the weakness of the subject in identifying the problem. Without knowing what they do not understand, subjects cannot make plans to fill the gaps in their knowledge (Erickson \& Heit, 2015). As a result, the subject does not know what to do in the problem solving process.

The fifth stage is carrying out problem-solving planning. At this stage, the subject applied the chosen approach and combined several approaches. This can be seen in the following interview transcript:

I: "How do you find a solution to this problem?

S: "At first I thought it was the same square, but if we zoom it turns out that the square size is not the same, so

I decided to use pieces of paper"

I: "Fine, please explain how the process is?"

S: "So I put a small piece of paper on the top like this, then I marked using a pen to ensure the size, there are two kinds of squares of different sizes (shown in figure 3 with numbers 1 and 2), so I give the name of white as big as 8, white as small as 24, shading the most big as much as 8 , shading as small as 24" 


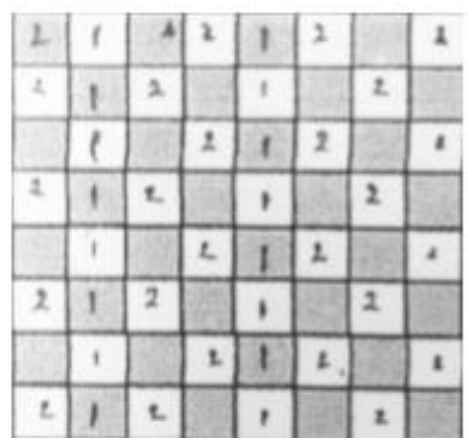

Figure 3. Subject's solving-problem sketch

According to the metacognition model, subjects will stop learning when they believe that they are experts in the topic (Son \& Sethi, 2010). This is what happened to the subjects in this study. In other words, the bias explained that, students who feel expert in a topic have excessive self-confidence which makes them reluctant to learn to accept new information. This phenomenon needs to be realized, so that good academic ability often backfires and is actually detrimental.

The final stage of problem solving is verification (re-checking solutions) to ensure that there are no calculation errors, concept errors, or procedural errors. This can be seen in the following interview transcript:

I: "Are you sure about this answer?"

S: "Yes, I'm sure, ma'am"

I: "What do you think of the problem presented here?"

$S:$ "Very challenging, ma'am ... it demands precision and critical thinking"

Until the final stages of problem solving, AR type redflags that occur in subjects are still consistent. This means, the existence of AR is permanent. As a result, the subject experiences total metacognitive blindness where he is unable to realize that the errors/ peculiarities he discovers during the process of problem solving actually never exist.

\section{CONCLUSION}

Based on the data analysis and findings, it can be concluded that subjects who have good academic performance tend to have excessive confidence. This makes the performance in the problem-solving process less optimal. It should also be noted that the redflag that occurs in subjects who are too confident is settled and permanent. That is, redflag can be found at all stages of problem-solving. As a result, the subject will experience total metacognitive blindness. Need more subsequently research, whether this pattern of metacognitive blindness also applied to other types of mathematical problems. Future studies are expected to also be able to involve subjects in greater numbers so as to produce stronger data analysis.

\section{REFERENCES}

Alexander, J. M., Carr, M., \& Schwanenflugel, P. J. (1995). Development of metacognition in gifted children: directions for future research. Developmental Review, 15(1), 1-37.

Creswell, J. W. (2012). Research design pendekatan kualitatif, kuantitatif dan mixed. Yogyakarta: Pustaka Belajar.

Dörr, L., \& Perels, F. (2019). Improving metacognitive abilities as an important prerequisite for self-regulated learning in preschool children. International Electronic Journal of Elementary Education, 11(5), 449-459.

Dunlosky, J., Hertzog, C., Kennedy, M., \& Thiede, K. (2005). The self-monitoring approach for effective learning. International Journal of Cognitive Technology, 10(1), 4-11. 
Dunning, D., Johnson, K., Ehrlinger, J., \& Kruger, J. (2003). Why people fail to recognize their own incompetence. Current Directions in Psychological Science, 12, 83-87.

Erickson, S., \& Heit, E. (2015). Metacognition and confidence: Comparing math to other academic subject. Frontiers in Psychology, 6, 742.

Faradiba, S. S., Sadijah, C., Parta, I. N., \& Rahardjo, S. (2019a). Metacognitive therapy for mathematics disorder. In Journal of Physics: Conference Series (Vol. 1157, No. 4, p. 042079). IOP Publishing.

Faradiba, S. S., Sa'dijah, C., Parta, I. N., \& Rahardjo, S. (2019b). Looking without seeing: the role of metacognitive blindness of student with high math anxiety. International Journal of Cognitive Research in Science, Engineering and Education (IJCRSEE), 7(2), 53-65.

Fraenkel, J. R., \& Wallen, N. E. (2006). How to design and evaluate research in education $\left(6^{\text {th }}\right.$ ed.). New York: McGraw-Hill.

Glaser, R., Schauble, L., Raghavan, K., \& Zeitz, C. 1992. Scientific reasoning across different domains. In E. de Corte, M. C. Linn, H. Mandl, \& L. Verschaffel (Eds.), ComputerBased Learning Environments and Problem Solving (pp. 345-371). Berlin Heidelberg: Springer Verlag.

Goos, M. (2002). Understanding metacognitive failure. Journal of Mathematical Behaviour, 21(3), 283-302.

Goos, M., Galbraith, P., \& Renshaw, P. (2000). A money problem: A source of insight into problem solving action. International Journal for Mathematics Teaching and Learning, 1(3), 1-21.

Hassan, N., \& Rahman, S. (2012). Problem solving skills, metacognitive awareness, and mathematics achievement: A mediation model. New Educational Review, 49(3), 201212.

Jacobse, A. E., \& Harskamp, E. G. (2012). Towards efficient measurement of metacognition in mathematical problem solving. Metacognition Learning, 7, 133-149.

Kim, Y. R., Park, M. S., Moore, T. J., \& Varma, S. (2013). Multiple levels of metacognition and their elicitation through complex problem-solving tasks. The Journal of Mathematical Behaviour, 32(3), 377-396.

Kruger, J., \& Dunning, D. (1999). Unskilled and unaware of it: how difficulties in recognizing one's own incompetence lead to inflated self-assessments. Journal of Personality and Social Psychology, 77(6), 1121-1134.

Legg, A., \& Locker, L. (2009). Math performance and its relationship to math anxiety and metacognition. North American Journal of Psychology, 11(3), 471-486.

Metcalfe, J., \& Finn, B. (2008). Evidence that judgments of learning are causally related to study choice. Psychonomic Bulletin and Review, 15(1), 174-179.

Miller, T. M., \& Geraci, L. (2011). Unskilled but aware: Reinterpreting overconfidence in lowperforming students. Journal of Experimental Psychology: Learning, Memory and Cognition, 37(2), 502-506.

$\mathrm{Ng}$, K. E. (2010). Partial metacognitive blindness in collaborative problem solving. Shaping the future of mathematics education: Proceedings of the 33rd annual conference of The Mathematics Education Research Group of Australasia (pp.446-453). Fremantle: Merga.

Safari, Y., \& Arezy, S. (2012). Improving students' educational performance using strategic metacognitive training. Modern Journal of Education (MJE), 1(10-11), 27-31.

Son, L. K., \& Sethi, R. (2010). Adaptive learning and the allocation of time. Adaptive Behavior, 18(2), 132-140. 
International Journal on Teaching and Learning Mathematics

2019, Vol. 2, No. 2, pp. 52-59

P-ISSN: 2621-2188, E-ISSN: 2621-2196

Stillman, G. (2004). Strategies employed by upper secondary students for overcoming or exploiting conditions affecting accessibility of applications tasks. Mathematics Education Research Journal, 16(1), 41-70.

Swanson, H. L. (1990). Influence of metacognitive knowledge and aptitude on problem solving. Journal of Educational Psychology, 82(2), 306-314.

Wismath, S., Orr, D., \& Good, B. (2014). Metacognition: Student reflections on problem solving. Journal on Excellence in College Teaching, 25(2), 69-90. 